\title{
Inherited NBN Mutations and Prostate Cancer Risk and Survival
}

\section{Bogna Rusak, MSc ${ }^{1}$ \\ Wojciech Kluźniak, $\mathrm{PhD}^{1}$ \\ Dominika Wokołorczykv, PhD \\ Klaudia Stempa, MSc ${ }^{\top}$ \\ Aniruddh Kashyap, MD' \\ Jacek Gronwald, MD'1 \\ Tomasz Huzarski, MD',2 \\ Tadeusz Dębniak, MD' \\ Anna Jakubowska, $\mathrm{PhD}^{1,3}$ \\ Bartłomiej Masojć, MD ${ }^{4}$ \\ Mohammad R. Akbari, MD \\ Steven A. Narodv, MD 5 \\ Jan Lubiński, MD' \\ Cezary Cybulski, MD \\ The Polish Hereditary Prostate Cancer \\ Consortium*}

\begin{abstract}
${ }^{1}$ Department of Genetics and Pathology, International Hereditary Cancer Center Pomeranian Medical University, Szczecin, ${ }^{2}$ Department of Clinical Genetics and Pathology, University of Zielona Góra, Zielona Góra, ${ }^{3}$ Independent Laboratory of Molecular Biology and Genetic Diagnostics, Pomeranian Medical University, Szczecin, ${ }^{4}$ West Pomeranian Oncology Center, Szczecin, Poland, ${ }^{5}$ Women's College Research Institute, University of Toronto, Toronto, Canada
\end{abstract}

\section{Purpose}

The purpose of this study was to establish the contribution of four founder alleles of NBN to prostate cancer risk and cancer survival.

\section{Materials and Methods}

Five thousand one hundred eighty-nine men with prostate cancer and 6,152 controls were genotyped for four recurrent variants of NBN (657del5, R215W, I171V, and E185Q).

\section{Results}

The NBN 657del5 mutation was detected in 74 of 5,189 unselected cases and in 35 of 6,152 controls (odds ratio [OR], 2.5; $p<0.001$ ). In carriers of 657 del5 deletion, the cancer risk was restricted to men with the GG genotype of the E185Q variant of the same gene. Among men with the GG genotype, the OR associated with 657 del5 was 4.4 (95\% confidence interval [Cl], 2.4 to 8.0). Among men with other E185Q genotypes, the OR associated with 657 del5 was 1.4 ( $95 \% \mathrm{Cl}, 0.8$ to 2.4 ) and the interaction was significant (homogeneity $p=0.006$ ). After a median follow-up of 109 months, mortality was worse for 657 del 5 mutation carriers than for non-carriers (hazard ratio [HR], 1.6; $p=0.001$ ). The adverse effect of 657 del5 on survival was only seen on the background of the GG genotype of E185Q (HR, 1.9; $p=0.0004)$.

\section{Conclusion}

The NBN 657del5 mutation predisposes to poor prognosis prostate cancer. The pathogenicity of this mutation, with regards to both prostate cancer risk and survival, is modified by a missense variant of the same gene (E185Q).

Key words

NBN, NBS1, Mutation, Aggressive prostate cancer, Survival
Correspondence: Cezary Cybulski, MD Department of Genetics and Pathology, Pomeranian Medical University, Unii Lubelskiej 1, 71-252 Szczecin, Poland Tel: 48-914417250

Fax: 48-914417251

E-mail: cezarycy@pum.edu.pl

Received September 26, 2018

Accepted December 12, 2018

Published Online December 13, 2018

*The members of the group are listed at the end of this article. 


\section{Introduction}

Mutations in several genes predispose to prostate cancer, including BRCA2, BRCA1, CHEK2, NBN, ATM and HOXB13 [1-9]. Homozygous mutations in the NBN gene (also called NBS1) are responsible for the Nijmegen breakage syndrome (NBS), which is characterized by spontaneous chromosomal instability, immunodeficiency and a predisposition to cancer [10]. The protein product of the NBN gene is part of the genome surveillance complex responsible for DNA damage repair [11]. A 5-bp deletion in exon 6 of the NBN gene (657del5) is a founder mutation, which, in its homozygous state is present in the majority of NBS patients. Heterozygous carriers of the 657 del5 truncating mutation exhibit increased susceptibility to prostate cancer [5]. It is not clear if other $N B N$ variants (missense or truncating) predispose to cancer. It is important to define the range of pathogenic NBN mutations, because $N B N$ is included in a number of cancer test panels and it is incumbent upon the physician to accurately predict the risk of a reported variant [12]. To establish the contribution of four founder alleles in NBN to prostate cancer in Poland, and to measure the impact of these variants on risk and survival, we genotyped 5,189 men with prostate cancer and 6,152 controls.

\section{Materials and Methods}

\section{Patients}

We studied men with unselected prostate cancer who were diagnosed between 1999 and 2015 in 14 centers situated throughout Poland. This study was initiated in Szczecin in 1999 and was extended to include Białystok, Olsztyn in 2002 and Opole in 2003. Other centers began recruiting between 2005 and 2008 (Koszalin, Gdansk, Lublin, Łodź, Warszawa, Wrocław, Poznan, Rzeszów, Bydgoszcz, and Zabrze). Only men with newly diagnosed prostate cancer were invited to participate in this study. All cases were unselected for age, clinical characteristics (stage, grade, prostate-specific antigen [PSA] level at time of diagnosis), family history and treatment received. Study subjects were asked to participate at the time of diagnosis or during an outpatient visit to an oncology clinic. Sixty-one hundred thirty men were invited and of these, 5,235 (85.4\%) participated. All patients provided a blood sample within six months of diagnosis. The mean age of diagnosis was 67.8 years (range, 35 to 96 years). A family history was taken either by the construction of a family tree or the completion of a standardized questionnaire. All first- and second-degree relatives diagnosed with prostate cancer and the ages of diagnosis were recorded. Six hundred thirty-five men reported at least one first- or second-degree relative with prostate cancer (familial cases). In addition, information was recorded on PSA level at time of diagnosis, grade (Gleason score) and stage. The vital status and the date of death of all of the cases were requested from the Polish Ministry of the Interior and Administration in June 2016, and were obtained in July 2016. These data were available for 5,185 men with prostate cancer. Information on the specific treatment was not recorded. The study was approved by the Ethics Committee of the Pomeranian Medical University in Szczecin, Poland.

\section{Genotyping}

DNA was isolated from 5 to $10 \mathrm{~mL}$ of peripheral blood. NBN mutations were genotyped using TaqMan assay (Thermo Fisher Scientific, Waltham, MA) using LightCycler RealTime PCR 480 System (Roche Life Science, Indianapolis, IN). Laboratory technicians were blinded to case-control status. Four NBN variants were successfully analyzed in 5,189 of 5,235 cases $(99.1 \%)$ and in 6,152 of 6,240 controls $(98.6 \%)$.

\section{Sanger sequencing}

To investigate whether other $N B N$ variants (i.e., those linked to the G allele of E185Q) may affect cancer risk among carriers of the 657del5 mutation, we sequenced the entire coding sequence of the NBN gene in 16 cancer patients with 657del5 (8 with the GG genotype of E185Q and 8 with the GC genotype). Sanger sequencing was performed in 16 amplicons. Sequencing reactions were performed using a BigDye Terminator v3.1 Cycle Sequencing Kit (Thermo Fisher Scientific) according to the manufacturer's protocol. Sequencing products were analyzed on the ABI prism 3500XL Genetic Analyzer (Thermo Fisher Scientific).

\section{Controls}

The control group included 6,240 cancer-free adults from (the genetically homogeneous population of) Poland. The control group consisted of 3,166 cancer-free men ages 23-90 years (mean age, 62.2 years) and 3,070 cancer-free women age 18 to 94 years (mean age, 54.0 years) [13,14]. The purpose of the control group was to estimate with accuracy the frequency of founder alleles of NBN in the underlying Polish population. The allele frequencies for all $N B N$ variants in our control group were not dependent on age, sex, and the prevalence estimates of all mutations were similar in younger and in older controls. The frequency of NBN 657del5 truncating mutation in our controls and in 6,984 (non-overlap- 
Table 1. Effect of $N B N$ variants on prostate cancer risk

\begin{tabular}{|c|c|c|c|c|c|c|c|}
\hline \multirow{2}{*}{$N B N$ variant } & \multicolumn{3}{|c|}{ Unselected prostate cancer cases } & \multicolumn{3}{|c|}{ Familial prostate cancer cases } & \multirow{2}{*}{$\begin{array}{c}\text { Control } \\
\text { No./Total }(\%)\end{array}$} \\
\hline & No./Total (\%) & OR $(95 \% \mathrm{CI})$ & p-value & No./Total $(\%)$ & OR $(95 \% \mathrm{CI})$ & p-value & \\
\hline 657del5 & $74 / 5,189(1.4)$ & $2.5(1.7-3.8)$ & $<0.001$ & $15 / 635(2.4)$ & $4.2(2.3-7.8)$ & $<0.001$ & $35 / 6,152(0.6)$ \\
\hline R215W & $13 / 5,189(0.25)$ & $1.3(0.5-3.4)$ & 0.762 & $2 / 635(0.3)$ & $1.6(0.3-8.2)$ & 0.889 & $6 / 3,122^{\text {a) }}(0.2)$ \\
\hline I171V & $140 / 5,189(2.7)$ & $1.2(0.9-1.5)$ & 0.351 & $8 / 635(1.3)$ & $0.5(0.3-1.1)$ & 0.120 & $73 / 3,122^{a)}(2.3)$ \\
\hline $\begin{array}{l}\text { E185Q } \\
\text { (GG genotype) }\end{array}$ & $2,207 / 5,189(42.6)$ & $1.0(0.9-1.1)$ & 0.994 & $270 / 634(42.6)$ & $1.0(0.8-1.2)$ & 0.982 & $2,617 / 6,152(42.5)$ \\
\hline $\begin{array}{l}\text { E185Q } \\
\text { (GC genotype) }\end{array}$ & $2,389 / 5,189(46.0)$ & $1.0(0.9-1.1)$ & 0.565 & $287 / 634(45.3)$ & $1.0(0.8-1.2)$ & 0.952 & $2,798 / 6,152(45.5)$ \\
\hline $\begin{array}{l}\text { E185Q } \\
\text { (CC genotype) }\end{array}$ & $593 / 5,189(11.4)$ & $0.9(0.8-1.1)$ & 0.379 & $77 / 518(12.1)$ & $1.0(0.8-1.3)$ & 0.954 & $737 / 6,152(12.0)$ \\
\hline
\end{tabular}

OR, odds ratio; CI, confidence interval. ${ }^{\mathrm{a}}$ For $R 215 \mathrm{~W}$ and $\mathrm{R} 215 \mathrm{~W}$ variants 3,122 controls were only genotyped.

ping) controls genotyped by Chrzanowska et al. [15] is $0.6 \%$.

\section{Statistical analysis}

\section{1) Odds ratios}

The prevalences of all alleles in cases and controls were compared. Odds ratios (OR) were generated from twoby-two tables and statistical significance was assessed using the Fisher exact test or the chi-square test where appropriate. The ORs were used as estimates of relative risk. The Breslow-Day test was used for testing the homogeneity of ORs.

\section{2) Survival analysis}

For the survival analysis, the patients were followed from the date of biopsy until death or June 2016. The median follow-up was 109 months. Kaplan-Meier survival curves were constructed for carriers of mutations and for non-carriers. Comparison of survival curves was performed by log-rank test. Detailed clinical information was available for a subset of 2,219 patients (PSA level at diagnosis, tumor stage, and Gleason score). A multivariable Cox regression analysis was performed on these patients.

\section{Ethical statement}

The study was approved by the Ethics Committee of the Pomeranian Medical University in Szczecin, Poland (IRB No. KB-0012/97/17) and performed in accordance with the principles of the Declaration of Helsinki. All patients and controls provided written informed consent.

\section{Results}

The NBN 657del5 mutation was detected in 74 of 5,189 unselected cases $(1.4 \%)$ compared to 35 of 6,152 controls $(0.6 \%)(\mathrm{OR}, 2.5 ; \mathrm{p}<0.001)$. It was present in 15 of 635 familial cases $(2.4 \%)(\mathrm{OR}, 4.2 ; \mathrm{p}<0.001)$.

None of the three missense variants was associated with prostate cancer risk (Table 1). However, we looked for possible interactions between NBN variants and we found a significant interaction between the 657del5 mutation and the E185Q variant (Table 2). Men with the GG genotype of the E185Q polymorphism and the 657del5 mutation were at four-fold elevated risk of prostate cancer (OR, 4.4; 95\% confidence interval [CI], 2.4 to 8.8). Among men with other E185Q genotypes (GC and GG), the 657del5 deletion was not associated with an increased risk of prostate cancer (OR, 1.4; 95\% CI, 0.8 to 2.4). The statistical test to reject homogeneity of the OR was highly significant $(\mathrm{p}=0.006)$. A similar association was seen among men with familial prostate cancer. Among men with the NBN GG genotype of E185Q, the OR for familial prostate cancer associated with truncating 657del5 mutation was 7.2 (95\% CI, 3.1 to 16.3). Among men with other E185Q genotypes of NBN (GC and CC), the 657del5 deletion was not associated with statistically significant increase in the risk of familial prostate cancer (OR, 2.3; 95\% CI, 0.9 to 6.2 ; homogeneity $\mathrm{p}$-value $=0.080$ ).

The characteristics of the prostate cancers in the $657 \mathrm{del} 5$ mutation carriers and non-carriers are presented in Table 3. Among carriers of the NBN 657del5 mutation, 39\% were of advanced stage at diagnosis, compared to $25 \%$ of those cases with no NBN variant (men who tested negative for the 657del5 deletion and for the GG genotype of E185Q). However, the stage difference was restricted to 657del5 carriers who also had the GG genotype of E185Q. Among 657del5 
Table 2. Effect of NBN 657del5 on prostate risk among studied groups, by genotype of the E185Q missense variant

\begin{tabular}{l} 
Variants present \\
\cline { 2 - 5 }
\end{tabular}

OR, odds ratio; $\mathrm{CI}$, confidence interval.

Table 3. Clinical characteristics of prostate cancers in carries of variant alleles in NBN

\begin{tabular}{|c|c|c|c|c|c|c|c|}
\hline & $\begin{array}{c}657 \text { del5 } \\
\text { mutation } \\
(n=74)\end{array}$ & p-value & $\begin{array}{c}\text { 657del5 and } \\
\text { E185Q GG } \\
\text { genotype }(n=50)\end{array}$ & p-value & $\begin{array}{c}\text { 657del5 and } \\
\text { E185Q non-GG } \\
\text { genotype }(n=24)\end{array}$ & p-value & $\begin{array}{l}\text { Neither } \\
\text { genotype }^{a)} \\
(n=2,958)\end{array}$ \\
\hline \multicolumn{8}{|c|}{ Age of diagnosis (yr) } \\
\hline Mean & 67.0 & 0.505 & 67.0 & 0.586 & 67.0 & 0.697 & 67.8 \\
\hline \multicolumn{8}{|c|}{ PSA level at diagnosis (ng/mL) } \\
\hline Median & 11.7 & 0.592 & 13.4 & 0.237 & 8.6 & 0.532 & 11.8 \\
\hline$\leq 4.0$ & $1 / 44(2.3)$ & 0.724 & $1 / 27(3.7)$ & 1.000 & $0 / 17(0.0)$ & 1.000 & $86 / 1,652(5.2)$ \\
\hline $4.1-10$ & $17 / 44(38.6)$ & 1.000 & $6 / 27(22.2)$ & 0.077 & $11 / 17(64.7)$ & 0.044 & $647 / 1,652(39.2)$ \\
\hline $10.1-20.0$ & $11 / 44(25.0)$ & 1.000 & $9 / 27(33.3)$ & 0.367 & 2/17 (11.8) & 0.271 & $407 / 1,652(24.6)$ \\
\hline$>20.0$ & $15 / 44(34.1)$ & 0.742 & $11 / 27(40.7)$ & 0.297 & $4 / 17(23.5)$ & 0.607 & $512 / 1,652(30.1)$ \\
\hline \multicolumn{8}{|c|}{ Gleason score } \\
\hline$<7$ & $25 / 54(47.2)$ & 0.522 & $17 / 36(47.2)$ & 0.618 & $8 / 18(44.4)$ & 0.638 & $1,011 / 1,957$ (51.7) \\
\hline 7 & $15 / 54(28.3)$ & 0.892 & $8 / 36(22.2)$ & 0.460 & $7 / 18(38.9)$ & 0.438 & $579 / 1,957(29.6)$ \\
\hline$>7$ & $14 / 54(24.5)$ & 0.250 & $11 / 36(30.6)$ & 0.085 & $3 / 18(16.7)$ & 1.000 & $367 / 1,957$ (18.7) \\
\hline \multicolumn{8}{|l|}{ Stage } \\
\hline $\mathrm{T} 1$ & $14 / 49(28.6)$ & 0.755 & $7 / 32(21.9)$ & 0.256 & $7 / 17(41.2)$ & 0.437 & $467 / 1,467$ (31.8) \\
\hline $\mathrm{T} 2$ & $16 / 49(32.7)$ & 0.186 & $11 / 32(34.4)$ & 0.370 & $5 / 17(29.4)$ & 0.328 & $632 / 1,467(43.1)$ \\
\hline $\mathrm{T} 3$ & $8 / 49$ (16.3) & 0.852 & $5 / 32(15.6)$ & 0.820 & $3 / 17(17.6)$ & 1.000 & $272 / 1,467(18.5)$ \\
\hline $\mathrm{T} 4$ & $11 / 49(22.4)$ & 0.0004 & $9 / 32(28.1)$ & 0.0002 & $2 / 17(11.8)$ & 0.311 & $96 / 1,467(6.5)$ \\
\hline $\mathrm{T} 3$ or $\mathrm{T} 4$ & $19 / 49(38.8)$ & 0.044 & $14 / 32(43.7)$ & 0.023 & $5 / 17(29.4)$ & 0.778 & $368 / 1,467(25.1)$ \\
\hline
\end{tabular}

Values are presented as number $(\%)$ unless otherwise indicated. ${ }^{a}$ p-values are calculated with respect to carriers of neither genotype (657del5 negative and E185Q GG genotype negative cases) as reference group.

carriers with the adverse GG allele, the proportion with advanced stage was $44 \%$ compared to $25 \%$ cases with no NBN variant $(\mathrm{p}=0.023)$. Among 657del5 carriers with other E185Q genotypes (GC and CC), advanced stage was present in only $29 \%$, which is comparable to that of the non-carrier cases $(25 \%, \mathrm{p}=0.778)$.

We obtained data about the presence of distant metastasis at diagnosis for 257 patients: of these, 37 patients had evidence of metastasis (M1) and 220 had no evidence of metastasis (M0). The frequency of NBN 657del5 mutation was particularly high among patients with metastatic disease $(4 / 37,10.8 \%)$ compared to those with no evidence of metastasis $(1 / 220,0.5 \%)$. All four men with metastatic disease and the $657 \mathrm{del} 5$ mutation carried the GG genotype of E185Q. 
Table 4. Survival of men with prostate cancer; by variant alleles of NBN

\begin{tabular}{|c|c|c|c|c|}
\hline & $\begin{array}{c}\text { Men with } \\
\text { 657del5 } \\
\text { mutation }(n=74)\end{array}$ & $\begin{array}{c}\text { Men with } 657 \text { del5 } \\
\text { and E185Q GG } \\
\text { genotype }(n=50)\end{array}$ & $\begin{array}{l}\text { Men with 657del5 } \\
\text { and E185Q non-GG } \\
\text { genotype }(n=24)\end{array}$ & $\begin{array}{c}\text { Men with } \\
\text { neither genotype } \\
(n=2,956)\end{array}$ \\
\hline Median follow-up (mo) & 90 & 90 & 87 & 106 \\
\hline Proportion of deceased $(\%)$ & 56.8 & 62.0 & 45.8 & 43.8 \\
\hline Median survival (mo) & 81 & 78 & 95 & 132 \\
\hline 5-Year survival $(\%)$ & 56 & 51 & 66 & 69 \\
\hline 10 -Year survival $(\%)$ & 34 & 28 & 45 & 53 \\
\hline HR & 1.6 & 2.0 & 1.1 & $1.0^{\mathrm{a})}$ \\
\hline $95 \% \mathrm{CI}$ & $1.1-2.5$ & $1.2-3.2$ & $0.6-2.2$ & - \\
\hline $\mathrm{p}$-value & 0.001 & 0.0001 & 0.659 & - \\
\hline
\end{tabular}

Hazard ratio (HR), 95\% confidence interval (CI), and p-values are calculated by log-rank test. ${ }^{a}$ Reference group (men with prostate cancer without 657del5 and without GG genotype of E185Q.

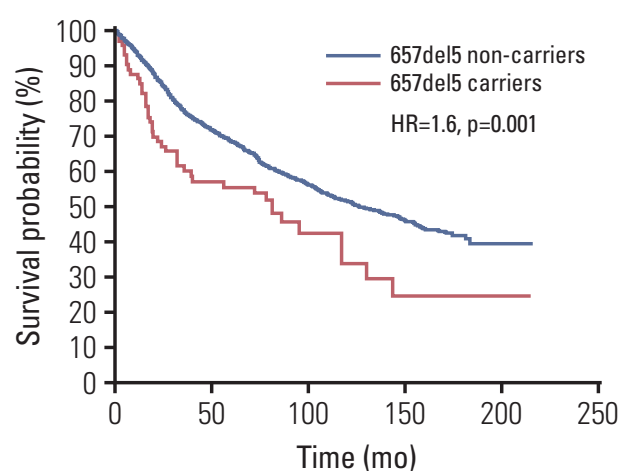

No. at risk

\begin{tabular}{|c|c|c|c|c|c|}
\hline 657del5 non-carriers & 5,111 & 3,353 & 1,557 & 238 & 11 \\
\hline 657del5 carriers & 74 & 35 & 11 & 4 & 1 \\
\hline
\end{tabular}

Fig. 1. Kaplan-Meier curves of prostate cancer patients with 657del5 mutation in NBN, compared with prostate cancer patients without $657 \mathrm{del} 5$ variant (non-carriers). HR, hazard ratio.

Data on survival was available for 5,185 men with prostate cancer (Table 4). After a median follow-up of 109 months there were 42 deaths $(56.7 \%)$ among 74 carriers of NBN 657 del5 mutation and 2,271 deaths (44.4\%) among 5111 noncarriers. The median survival was 81 months for $657 \mathrm{del} 5 \mathrm{car}-$ riers compared to 129 months for non-carriers (HR, 1.63; 95\% CI, 1.1 to 2,$4 ; p=0.001$, log-rank test) (Fig. 1 ). The 10 -year survival was $34 \%$ for $657 \mathrm{del} 5$ carriers compared to $53 \%$ for noncarriers. After adjusting for age of diagnosis, PSA, stage and grade, the HR for mortality associated with NBN 657del5 mutation was 1.52 ( $95 \% \mathrm{CI}, 1.1$ to 2.2; $\mathrm{p}=0.023$ ) (S1 Table).

Survival was modified according to the background of E185Q missense variant. There were 31 deaths (62\%) recor- ded in 50 carriers of NBN 657del5 mutation and the GG genotype, and 975 deaths (45.2\%) in 2,155 men without 657 del5 but with the GG genotype of E185Q. Among all men with the GG genotype of E185Q, survival experience was significantly worse for carriers of 657del5 NBN mutation, compared to non-carriers (HR, 1.9; $\mathrm{p}=0.0004$, log-rank test; 10 year survival $28 \%$ vs. $53 \%$, respectively) (Fig. 2). Among men with other alleles of E185Q (GC and CC), survival experience was similar for carriers of 657del5 NBN mutation and non-carriers (HR, 1.1; $p=0.659$; 10-year survival $45 \%$ vs. $53 \%$, respectively).

To investigate whether other NBN variants (i.e., those linked to the $\mathrm{G}$ allele of $\mathrm{E} 185 \mathrm{Q}$ ) may affect cancer risk among carriers of the 657del5 mutation, we sequenced the NBN gene in 16 prostate cancer patients (8 with the GG genotype of E185Q and 8 without) but we did not detect any other coding variants in sequence of the NBN gene.

\section{Discussion}

Here we extend our earlier work which established NBN 657 del5 as a prostate cancer susceptibility allele [5,14]. In our previous study, we genotyped 3,750 prostate cancer cases and 3,956 controls for a single truncating mutation in NBN (657del5). We have enlarged our series to include 5,189 men with prostate cancer and 6,152 controls and we genotyped all subjects for four recurrent variants of NBN (657del5, R215W, I171V, and E185Q).

Recently Mijuskovic et al. [16] sequenced germline whole exomes from 139 aggressive (metastatic, age of diagnosis $<60$ ) and 141 non-aggressive (low clinical grade, age of 
A

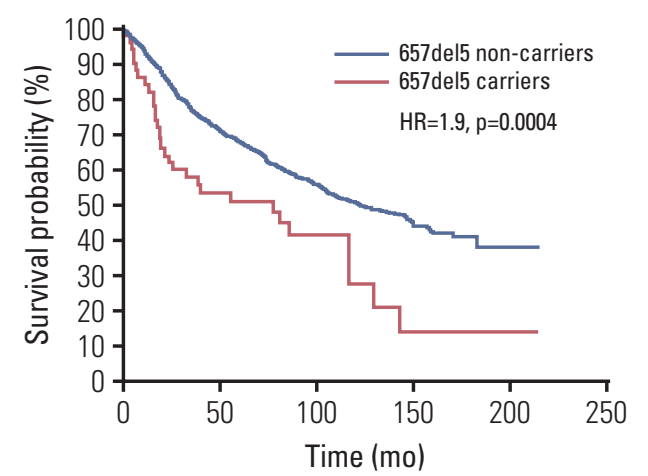

No. at risk

$\begin{array}{crrrrrr}657 \text { del5 non-carriers } & 2,155 & 1,385 & 662 & 102 & 6 & 0 \\ 657 \text { del5 carriers } & 50 & 20 & 7 & 2 & 1 & 0\end{array}$

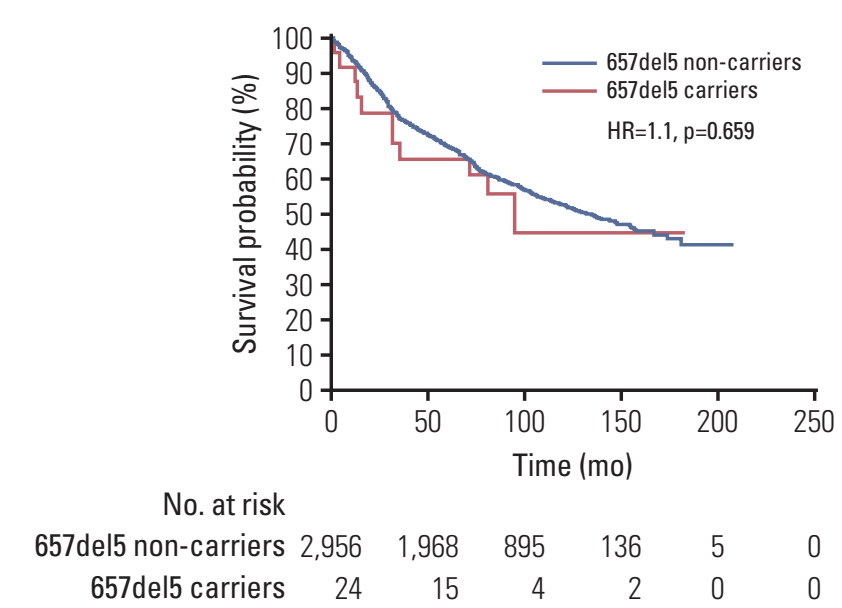

Fig. 2. Kaplan-Meier curves of prostate cancer patients with a 657del5 mutation in NBN and non-carriers: on the GG genotype background of E185Q (A); on the non-GG (GC and CC) genotype background of E185Q (B).

diagnosis $\geq 60$ ) prostate cancer cases from the United Kingdom, and found that truncating variants of NBN were significantly enriched among patients with the aggressive phenotype. Two other studies explored the association between NBN and prostate cancer risk. In first study, the 657 del 5 allele was seen in seven of 3,037 men with prostate cancer $(0.23 \%)$ and in none of 990 unaffected controls in the United States [17]. The clinical characteristics of the mutation positive cases are not described. In the second study, 94 familial prostate cancer cases from the USA were screened by whole exomesequencing. A novel truncating mutation of NBN, $(2117 \mathrm{C}>\mathrm{G}$ mutation that results in a premature stop at codon 706 (S706X) was detected in one family [18].

In the current study we also investigated the potential pathogenicity of three missense variants of NBN. These three variants (E185Q, R215W, I171V) were selected from over 84 known missense variants in NBN on the basis of suggestive prior evidence of pathogenicity and because they are founder alleles in the Polish population [19-25]. None of the three missense variants was associated with prostate cancer risk in the current study. However, in an examination of potential interactions between all four NBN variants an interesting pattern emerged. The excess cancer risk in carriers of 657 del 5 deletion was restricted to the subgroup of men who were homozygous for the GG genotype in codon 185 of the same gene. Among men with the GG genotype of E185Q, the OR associated with a truncating 657del5 mutation was 4.4 (95\% CI, 2.4 to 8.0). Among men with other E185Q genotypes (GC and $\mathrm{CC})$, the $657 \mathrm{del} 5$ deletion was not associated with prostate cancer (OR, 1.4; 95\% CI, 0.8 to 2.4 ; homogeneity $\mathrm{p}=0.006)$. We saw a similar modifying effect of the E185Q GG allele on the pathogenicity of 657del5 when we studied clinical presentation and survival. The adverse effect of the 657del5 mutation on survival was present among carriers of the GG genotype of E185Q (HR, 1.9; $\mathrm{p}=0.0004$ ), but was not present among 657del5 carriers with other E185Q genotypes (HR, 1.1; $\mathrm{p}=0.659$ ). The two observations (the effect of E185Q on prostate cancer risk and prognosis among 657del5 mutation carriers) are independent, one validates the other. In addition, we saw similar interaction between these two NBN variants for risk of breast cancer (data not shown). Therefore, we propose that the pathogenicity of NBN 657del5 truncating mutation may be modified by the E185Q missense variant of the same gene.

To investigate whether other NBN variants (i.e., those linked to the $G$ allele of E185Q) may affect cancer risk among carriers of the $657 \mathrm{del} 5$ mutation, we sequenced the entire NBN gene in 16 prostate cancer patients (8 with the GG genotype of E185Q and 8 without) but we did not detect any other coding variants in sequence of the NBN gene. This suggests that the E185Q polymorphism may be the functional variant with regard to risk modification.

The NBN 657del5 mutation is predicted to generate two truncated proteins of 219 (p26) and 754 (p70) amino acids in length. p26 lacks a critical domain necessary for MRE11 interaction [26,27]. The G allele of E185Q is in complete linkage disequilibrium with the $657 \mathrm{del} 5$ mutation. It was observed that $68 \%$ of unselected prostate cancer cases with the deletion have the $\mathrm{G}$ allele and $32 \%$ of the carriers have the $\mathrm{C}$ allele on the other (non-mutant) chromosome. Our data suggest that among deletion carriers it is necessary that the normal copy of the NBN protein carry a glutamic acid residue at position 185 to confer susceptibility to prostate cancer. 
This observation has several clinical implications-we call into question the pathogenicity of the novel NBN mutations that have not been well studied-the risk of cancer is not the same for all $657 \mathrm{del} 5$ mutation carriers. It is important to establish the E185Q genotype status when counseling a carrier of a 657 del 5 deletion. Further, we question the practice of adding cancer susceptibility genes to testing panels before they have been well characterized for a range of truncating mutations in different ethnic populations.

Herein we describe a new model for inherited cancer susceptibility wherein the penetrance of a dominant cancer susceptibility gene is modified by other alleles of the same gene (in trans or in cis) which, on their own, do not increase risk. This phenomenon may explain to some degree why different risks of cancer have been reported for mutations in the same gene in different countries and further studies are needed in this regard. Based on these results, we consider it is premature to counsel men with truncating NBN mutations other than $657 \mathrm{del} 5$ that they are at increased risk of prostate cancer based on data derived from the single mutation, 657 del5. It will be important to study this paradigm in other cancer genes as well. We describe a poor survival of men with the NBN 657del5/E185Q GG genotype.

There is no organized prostate screening program in Poland and the majority of the patients in this study presented because of symptoms or because of an abnormal digital rectal examination. We believe that prostate cancer screening is warranted in NBN carriers, because of the high risk of cancer (OR, 4.4), the high likelihood of presenting clinically with advanced disease and because of the poor survival experience of those who present with clinical signs or symptoms. It is also important to determine if therapy beyond the conventional therapy is valuable for men with prostate cancer and a NBN mutation.

In conclusion, our results provide compelling evidence that a founder $657 \mathrm{del} 5$ mutation in NBN predisposes to aggressive prostate cancers and that the pathogenicity of this truncating mutation is modified by another allele of the same gene (E185Q).

\section{Electronic Supplementary Material}

Supplementary materials are available at Cancer Research and Treatment website (https:// www.e-crt.org).

\section{Conflicts of Interest}

Conflict of interest relevant to this article was not reported.

\section{Acknowledgments}

This study was funded by National Science Centre, Poland; project number: 2015/19/B / NZ2/02439.

We thank Daria Zanoza, for her support in this study.

\section{*The Polish Hereditary Prostate Cancer Consortium}

Other members of the Polish Hereditary Prostate Cancer Consortium: Adam Gołąb ${ }^{1}$, Barłłomiej Gliniewicz ${ }^{2}$, Andrzej Sikorski ${ }^{1}$, Marcin Słojewski ${ }^{1}$, Jerzy Świtała ${ }^{2}$, Tomasz Borkowski ${ }^{3}$, Andrzej Borkowski ${ }^{3}$, Andrzej Antczak ${ }^{4}$, Łukasz Wojnar ${ }^{4}$, Jacek Przybyła ${ }^{5}$, Marek Sosnowski ${ }^{5}$, Bartosz Małkiewicz ${ }^{6}$, Romuald Zdrojowy ${ }^{6}$, Paulina Sikorska-Radek ${ }^{7}$, Jozef Matych ${ }^{7}$, Jacek Wilkosz', Waldemar Rożański $^{8}$, Jacek Kisi ${ }^{9}$, Krzysztof Bar ${ }^{9}$, Piotr Bryniarski ${ }^{10}$, Andrzej Paradysz $^{10}$, Konrad Jersak ${ }^{11}$, Jerzy Niemirowicz ${ }^{11}$, Piotr Słupski ${ }^{12}$, Piotr Jarzemski $^{12}$, Michał Skrzypczyk ${ }^{13}$, Jakub Dobruch ${ }^{13}$, Paweł Domagała $^{14}$, Bohdan Gorski ${ }^{15}$, Tomasz Byrski ${ }^{16}$, Michał Puszyński ${ }^{2}$, Michał Soczawa ${ }^{1}$, Sławomir Archimowicz ${ }^{2}$, Mirosław Kordowski², Marcin Życzkowski ${ }^{10}$, Andrzej Borowka ${ }^{13}$, Joanna Bagińska ${ }^{17}$, Kazimierz Krajka $^{17}$, Marek Szwiec ${ }^{18}$, Małgorzata Stawicka ${ }^{19}$, Olga Haus ${ }^{20}$, Hanna Janiszewska ${ }^{20}$, Agnieszka Stembalska ${ }^{21}$, Maria Małgorzata Sąsiadek ${ }^{21}$

${ }^{1}$ Clinic of Urology, Pomeranian Medical University, Szczecin, ${ }^{2}$ Division of Urology, Maria Skłodowska-Curie Hospital, Szczecin, ${ }^{3}$ Department of Urology, Medical University, Warszawa, ${ }^{4}$ Chair of Urology, Medical University, Poznan, ${ }^{5}$ Department of Urology, Medical University of Lodz, Łodź, ${ }^{6}$ Department of Urology and Urological Oncology, University of Medicine, Wrocław, ${ }^{7}$ Division of Urology, Regional Hospital, Łódź, ${ }^{8}$ Second Department of Urology, Medical University of Lodz, Łodź, ' Department of Urology, University Hospital of Lublin, Lublin, ${ }^{10}$ Department of Urology, Medical University of Silesia, Zabrze, ${ }^{11}$ Department of Urology, Ministry of Internal Affairs and Administration Hospital, Łódź, ${ }^{12}$ Department of Urology, J. Biziel Hospital, Bydgoszcz, ${ }^{13}$ Department of Urology, Centre of Postgraduate Urology Education, Warsaw, ${ }^{14}$ Department of Pathology, Pomeranian Medical University, Szczecin, ${ }^{15}$ Department of Genetics and Pathology, Pomeranian Medical University, Szczecin, ${ }^{16}$ Department of Oncology, Pomeranian Medical University, Szczecin, ${ }^{17}$ Clinic of Urology, Medical University, Gdansk, ${ }^{18}$ Department of Clinical Oncology, University Hospital in Zielona Gora, ${ }^{19}$ Department of Clinical Genetics and Pathology, University of Zielona Góra, Zielona Góra, ${ }^{20}$ Department of Clinical Genetics, Nicolaus Copernicus University, Bydgoszcz, ${ }^{21}$ Department of Genetics, Wroclaw Medical University, Wrocław, Poland 


\section{References}

1. Struewing JP, Hartge P, Wacholder S, Baker SM, Berlin M, McAdams $M$, et al. The risk of cancer associated with specific mutations of BRCA1 and BRCA2 among Ashkenazi Jews. N Engl J Med. 1997;336:1401-8.

2. Dong X, Wang L, Taniguchi K, Wang X, Cunningham JM, McDonnell SK, et al. Mutations in CHEK2 associated with prostate cancer risk. Am J Hum Genet. 2003;72:270-80.

3. Edwards SM, Evans DG, Hope Q, Norman AR, Barbachano Y, Bullock S, et al. Prostate cancer in BRCA2 germline mutation carriers is associated with poorer prognosis. Br J Cancer. 2010; 103:918-24.

4. Seppala EH, Ikonen T, Mononen N, Autio V, Rokman A, Matikainen MP, et al. CHEK2 variants associate with hereditary prostate cancer. Br J Cancer. 2003;89:1966-70.

5. Cybulski C, Gorski B, Debniak T, Gliniewicz B, Mierzejewski M, Masojc B, et al. NBS1 is a prostate cancer susceptibility gene. Cancer Res. 2004;64:1215-9.

6. Kirchhoff T, Kauff ND, Mitra N, Nafa K, Huang H, Palmer C, et al. BRCA mutations and risk of prostate cancer in Ashkenazi Jews. Clin Cancer Res. 2004;10:2918-21.

7. Kote-Jarai Z, Leongamornlert D, Saunders E, Tymrakiewicz M, Castro E, Mahmud N, et al. BRCA2 is a moderate penetrance gene contributing to young-onset prostate cancer: implications for genetic testing in prostate cancer patients. $\mathrm{Br}$ J Cancer. 2011;105:1230-4.

8. Ewing CM, Ray AM, Lange EM, Zuhlke KA, Robbins CM, Tembe WD, et al. Germline mutations in HOXB13 and prostate-cancer risk. N Engl J Med. 2012;366:141-9.

9. Leongamornlert D, Mahmud N, Tymrakiewicz M, Saunders E, Dadaev T, Castro E, et al. Germline BRCA1 mutations increase prostate cancer risk. Br J Cancer. 2012;106:1697-701.

10. Varon R, Vissinga C, Platzer M, Cerosaletti KM, Chrzanowska KH, Saar K, et al. Nibrin, a novel DNA double-strand break repair protein, is mutated in Nijmegen breakage syndrome. Cell. 1998;93:467-76.

11. Carney JP, Maser RS, Olivares H, Davis EM, Le Beau M, Yates JR 3rd, et al. The hMre11/hRad50 protein complex and Nijmegen breakage syndrome: linkage of double-strand break repair to the cellular DNA damage response. Cell. 1998;93:47786.

12. Easton DF, Pharoah PD, Antoniou AC, Tischkowitz M, Tavtigian SV, Nathanson KL, et al. Gene-panel sequencing and the prediction of breast-cancer risk. N Engl J Med. 2015;372:224357.

13. Cybulski C, Wokolorczyk D, Jakubowska A, Huzarski T, Byrski T, Gronwald J, et al. Risk of breast cancer in women with a CHEK2 mutation with and without a family history of breast cancer. J Clin Oncol. 2011;29:3747-52.

14. Cybulski C, Wokolorczyk D, Kluzniak W, Jakubowska A, Gorski B, Gronwald J, et al. An inherited NBN mutation is associated with poor prognosis prostate cancer. Br J Cancer. 2013;108:461-8.

15. Chrzanowska KH, Piekutowska-Abramczuk D, Popowska E,
Gladkowska-Dura M, Maldyk J, Syczewska M, et al. Carrier frequency of mutation 657del5 in the NBS1 gene in a population of Polish pediatric patients with sporadic lymphoid malignancies. Int J Cancer. 2006;118:1269-74.

16. Mijuskovic M, Saunders EJ, Leongamornlert DA, Wakerell S, Whitmore I, Dadaev T, et al. Rare germline variants in DNA repair genes and the angiogenesis pathway predispose prostate cancer patients to develop metastatic disease. Br J Cancer. 2018;119:96-104.

17. Hebbring SJ, Fredriksson H, White KA, Maier C, Ewing C, $\mathrm{McDonnell} \mathrm{SK}$, et al. Role of the Nijmegen breakage syndrome 1 gene in familial and sporadic prostate cancer. Cancer Epidemiol Biomarkers Prev. 2006;15:935-8.

18. Zuhlke KA, Johnson AM, Okoth LA, Stoffel EM, Robbins CM, Tembe WA, et al. Identification of a novel NBN truncating mutation in a family with hereditary prostate cancer. Fam Cancer. 2012;11:595-600.

19. di Masi A, Antoccia A. NBS1 heterozygosity and cancer risk. Curr Genomics. 2008;9:275-81.

20. Zheng J, Zhang C, Jiang L, You Y, Liu Y, Lu J, et al. Functional NBS1 polymorphism is associated with occurrence and advanced disease status of nasopharyngeal carcinoma. Mol Carcinog. 2011;50:689-96.

21. Roznowski K, Januszkiewicz-Lewandowska D, Mosor M, Pernak M, Litwiniuk M, Nowak J. I171V germline mutation in the NBS1 gene significantly increases risk of breast cancer. Breast Cancer Res Treat. 2008;110:343-8.

22. Mendez G, Cilli D, Berardinelli F, Viganotti M, Ascenzi P, Tanzarella $\mathrm{C}$, et al. Cleavage of the BRCT tandem domains of nibrin by the $657 \mathrm{del} 5$ mutation affects the DNA damage response less than the Arg215Trp mutation. IUBMB Life. 2012;64:85361.

23. Gao P, Ma N, Li M, Tian QB, Liu DW. Functional variants in NBS1 and cancer risk: evidence from a meta-analysis of 60 publications with 111 individual studies. Mutagenesis. 2013; 28:683-97.

24. Fang W, Qiu F, Zhang L, Deng J, Zhang H, Yang L, et al. The functional polymorphism of NBS1 p.Glu185Gln is associated with an increased risk of lung cancer in Chinese populations: case-control and a meta-analysis. Mutat Res. 2014;770:61-8.

25. Ziolkowska-Suchanek I, Mosor M, Wierzbicka M, Fichna M, Rydzanicz M, Nowak J. Association of polymorphisms and haplotypes of the NBN gene with laryngeal cancer and multiple primary tumors of the head and neck. Head Neck. 2012; 34:376-83.

26. Maser RS, Zinkel R, Petrini JH. An alternative mode of translation permits production of a variant NBS1 protein from the common Nijmegen breakage syndrome allele. Nat Genet. 2001;27:417-21.

27. Kobayashi J, Antoccia A, Tauchi H, Matsuura S, Komatsu K. NBS1 and its functional role in the DNA damage response. DNA Repair (Amst). 2004;3:855-61. 